\title{
O DESAFIO DE SER PSICOTERAPEUTA: ARTICULAÇÕES ENTRE AS CLÍNICAS DE INSPIRAÇÃO HEIDEGGERIANA E WINNICOTTIANA
}

Celina Maria Aragão Ximenes

Universidade Católica de Pernambuco (UNICAP)

Mariana Peres Stucchi

Universidade Católica de Pernambuco (UNICAP)

Wellington Martins de Lira

Universidade Católica de Pernambuco (UNICAP)

\begin{abstract}
Resumo
O acolhimento na clínica psicológica surge como um dos maiores embates na contemporaneidade. Este artigo pretende refletir o ser psicoterapeuta em uma perspectiva que aproxime ainda mais da experiência de inclinar-se frente ao sofrimento do outro em uma atitude de acolhimento. Inspirados nos conceitos centrais de "cuidado" na clínica daseinsanalítica e de "holding" no pensamento winnicottiano, procura-se elucidar a temática, destacando o compromisso ético desse profissional no contexto da clínica psicológica. Para isso, será feito um breve esboço das características norteadoras da Daseinsanalyse e da clínica na perspectiva de Winnicott, destacando especificamente a figura do psicoterapeuta e suas implicações na relação com o outro. Possíveis arremates serão realizados entre esses diferentes olhares, salvaguardando a experiência imediata do que representa a sua prática. Em um último momento, pretende-se apontar o que tais articulações levam o profissional a pensar para além de uma clínica psicológica a serviço de uma adaptação ao contexto social.

Palavras-chave: psicoterapia; daseinsanalyse; clínica winnicottiana.
\end{abstract}

\section{THE CHALLENGE OF TO BE PSYCHOTHERAPIST: ARTICULATIONS BETWEEN INSPIRATION HEIDEGGERIAN AND WINNICOTTIAN CLINICAL}

\begin{abstract}
The welcoming in the clinical psychology appeared as one of the greatest clashes in contemporary times. This paper intends to reflect the be psychotherapist a perspective approaching ourselves even more of experience of to lean front to suffering of another in a welcoming attitude Inspired by the central concepts of "care" in daseinsanalytic clinic and "holding" in Winnicott's thinking, we will search for elucidate the theme, detaching the ethical commitment this professional in the context of psychological clinic. To this, we will make a brief outline of the guiding characteristics of Daseinsanalyse and of the clinic in Winnicott's perspective, specifically highlighting the figure of the psychotherapist and its implications in relation to the other; We will propose to make possible bind off between these different looks, safeguarding the immediate experience of what for us representing your practice. In a last moment, we will point out that such articulations lead us to think beyond a psychological clinic to service of an adaptation to the social context.
\end{abstract}

Keywords: psychotherapy; daseinsanalyse; Winnicott's clinic. 


\title{
EL RETO DE SER PSICOTERAPEUTA: ARTICULACIONES ENTRE LAS CLÍNICAS HEIDEGGERIANA Y WINNICOTTIANA
}

\begin{abstract}
Resumen
El anfitrión en clínica psicológica aparece como uno de los mayores choques en la contemporaneidad. Este artículo pretende reflejar el enfoque estadounidense perspectiva psicoterapeuta aún más experiencia para apoyarse en el sufrimiento de otro en actitud de saludo. Inspirado en los conceptos centrales de "prudencia" en la clínica daseinsanalítica y "explotación" en el pensamiento winnicottiano, intentaremos dilucidar el tema, destacando el compromiso ético que en el contexto de la clínica psicológica profesional. Para ello, haremos un breve resumen de las principales características de Daseinsanalysis y clínica en perspectiva de Winnicott, destacando en particular la figura del psicoterapeuta y sus implicaciones en relación con el otro; propondremos hacer caps posibles entre estas diferentes miradas, salvaguardar la experiencia inmediata que para nosotros representa su práctica. A último momento, consideramos que tales juntas nos llevan a pensar más allá de una clínica psicológica al servicio de una adaptación al contexto social.
\end{abstract}

Palabras clave: psicoterapia; daseinsanalysis; clínica winnicottiana.

\section{A CLÍNICA PSICOLÓGICA ${ }^{1}$ COMO CUIDADO DO SOFRIMENTO HUMANO}

As discussões entre linhas teóricas que embasam a terapêutica clínica no campo da psicologia passam por concepções de homem e de cura, primordialmente. Doron e Parot (1998) afirmam que, originariamente, o termo clínica (do grego Klinê = leito) traduz a atividade do médico que, à cabeceira do doente, examina as manifestações da doença para fazer um diagnóstico, um prognóstico e prescrever um tratamento. Nesse sentido, a ação clínica envolveria o uso da observação (das manifestações objetivas da doença), da entrevista (indagar, do doente, sobre aspectos mais ligados ao que ele sente, aos sintomas) e da prescrição (de medicamentos e/ou condutas). A primeira formulação mais abrangente e precisa do termo "clínica" deve-se a Lagache, durante uma conferência em 1949. A ideia foi retomada, alguns anos depois, por J. Favez-Boutonnier, tomando a clínica como uma postura geral relativa ao homem (sofredor ou não) e ao saber empregado nessa relação (Levy, 2001). Nessa perspectiva, a ênfase é na singularidade e na globalidade do sujeito, na sua história. A implicação do terapeuta e a pesquisa de estrutura e de sentido vão constituir os principais eixos da abordagem e demarché clínica.

A clínica teve seu surgimento ligado à medicina e, portanto, a um contexto de ajuda e cuidados proporcionados a um paciente acamado. Com o tempo, essa noção foi ampliada e transformada, como afirma Levy (2001). Em razão disso, diz o autor, existem inúmeras maneiras de "se inclinar" sobre o leito de uma pessoa que sofre, desde auscultá-la, observá-la, apalpá-la, até enxugar o suor,

\footnotetext{
1 Apesar de ambas as vertentes - a de inspiração heideggeriana e a Winnicottiana transitarem em diferentes registros de inteligibilidade do humano, é de acreditar que as possíveis aproximações, aqui propostas, permitirão um frutífero diálogo que, longe de apontarem divergências de pensamento, favorecerão a tematização daquilo que depreendemos como sendo a mais intrigante e desafiadora tarefa do psicoterapeuta na atualidade, propositura central deste trabalho, a ser esclarecido melhor no texto.
} 
escutar a queixa, dedicar-lhe compaixão, palavras tranquilizadoras e até prolongar seu sofrimento. Cada profissional (médico, paramédico, psicólogo, psicanalista, entre outros) atuará conforme suas concepções teóricas fundamentadas nos planos ético, filosófico ou religioso, de acordo com as representações do homem no mundo e de suas relações com os outros. Muito mais que um conjunto de métodos e técnicas, a clínica se depara com um posicionamento em relação ao outro, ao saber a sua elaboração, trazendo reflexões sobre teoria e prática, pesquisa e ação.

Uma abordagem clínica só tem sentido em uma relação mutuamente aceita, com todos os acasos, as dúvidas e incertezas que comporta. Há também uma demanda, cuja análise e tratamento são o centro da démarche clínica, seja individual ou coletiva. A demanda tem uma multiplicidade de aspectos. A clínica psicológica, herdada do modelo médico (higienista), cuja lógica era observar, compreender e tratar, permaneceu distante das questões sociais, por muito tempo. Guerra (2002) afirma que Freud e a psicanálise deslocaram a ação clínica fundamentada no olhar sobre o fenômeno para a atitude de escuta. Assim, a ação clínica psicológica passa a vincular-se à demanda do sujeito e não, necessariamente, à patologia. Porém, para o autor, a perspectiva individualista não é superada pelo freudismo, vez que a clínica proposta por Freud se detém a casos individuais cujas patologias deveriam ser buscadas na história de vida dos sujeitos imersos em um contexto social mais amplo.

Para Romagnolli (2006), no desafio de trilhar novos caminhos, o psicólogo tem a tarefa de estender sua ação para um número maior de pessoas e de classes sociais, bem como de produzir novos recursos em sua formação e novas formas de ação profissional capazes de construir práticas ético-políticas. Figueiredo (2004) afirma que o que caracteriza a clínica psicológica não é o local onde se realiza, mas a qualidade da escuta e da acolhida que se oferece ao sujeito. O autor (Figueiredo, 2004) define a clínica a partir de um "ethos" comprometido com a escuta do interditado e a sustentação das tensões e dos conflitos. O método clínico visa, portanto, à escuta do excluído, do virtual, do "não positivo" em uma dupla acepção: "o que não goza em princípio de valor elevado" e "o que não tem a positividade das coisas" que se possibilitaria às mesmas se mostrarem e serem nomeadas. Nesse sentido, Calazans (2008) entende a clínica como uma tentativa de modificação de posição subjetiva não pela correção objetiva, mas pela via da escuta do desejo. Na mesma direção, Dutra (2004) afirma que o ato clínico se caracteriza muito mais por uma ética do que por referenciais teóricos fechados.

Na clínica, o psicólogo precisa ser um facilitador a acolher e construir com o sujeito que sofre, diante das contradições e conflitos no mundo do trabalho, da família, da religião, co-construindo possibilidades de compreensão e ressignificação desse sofrimento. Nessa direção, para Figueiredo (2004), ser psicólogo, independentemente das escolhas teóricas de cada um, implica situar- 
se nos campos da epistemologia e da ética, não sendo jamais apenas uma fonte de habilidades técnicas. A clínica é, portanto, uma possibilidade de produção e não de reprodução. É uma forma de resistência, conforme Romagnolli (2006).

A partir do pensamento de Heidegger, construindo uma visão de mundo e de homem, enfatizando o existir e a indissociabilidade de um com o outro, alguns autores criaram uma concepção de clínica. De um lado, a daseinsanalítica representada pelo psiquiatra Medard Boss, prima pela noção de Dasein proposta por Heidegger na obra "Ser e tempo" (1927), na intenção de compreender modos de ser do homem; de outro, a clínica winnicottiana se preocupa especialmente com os primeiros momentos de vida, com a relação de cuidado que permite ao bebê se constituir para poder viver criativamente na relação com o mundo. Sendo assim, pretende-se apresentar, de modo sucinto, o desenvolvimento da clínica psicológica nessas duas vertentes especificamente e, em seguida, traçar alguns paralelos que vemos como importantes e éticos para o cuidado clínico nesse contexto, uma vez que muitas abordagens estão sentindo suas limitações frente aos sofrimentos psíquicos que se apresentam intensa e frequentemente sob a forma de doenças psicossomáticas, transtornos alimentares, pânico, depressão, entre outras.

\section{Alguns fragmentos da clínica psicológica}

\section{A clínica daseinsanalítica}

A clínica daseinsanalítica, incrustada no pensamento heideggeriano, destaca a fragilidade presente nas ciências em geral, em especial, na medicina, na psicologia e na sociologia que, consolidadas em um modo de pensar mecanicista, demonstram impossibilidade de dar perspectivas e metas terapêuticas significativas. Afirma Heidegger (2001b): "Vivemos em uma época estranha, singular e inquietante. Quanto mais a quantidade de informações aumenta de modo desenfreado, tanto mais decididamente se ampliam o ofuscamento e a cegueira diante dos fenômenos" (p. 101-102). Complementa o autor (2001b): "[...] não se pergunta mais quem e como é o homem; em vez disso, ele é representado a priori a partir da manipulabilidade técnica do mundo" (p. 167).

A clínica daseinsanalítica, de um lado, consolidada substancialmente no plano ôntico, na concretude de uma existência delineada em dado momento histórico, tematiza os fenômenos considerados normais e patológicos do existir humano; de outro, visa a articular os muitos modos de ser do homem em seus incessantes movimentos de busca de sentido da vida, razão pela qual transita também no plano ontológico. No contexto dessa clínica, há um modo geral de ser do homem, expresso na sua condição finita (plano ontológico), no entanto, vivido e expresso por cada ser humano singularmente (ôntico). Segundo Heidegger (2001b), o homem enquanto Dasein, uma vez lançado no mundo, é ser de 
angústia, apresentando-se permanentemente envolvido em uma intrigante trama de sentidos e significados que constitui o seu mundo, servindo apenas de "clareira", zona de abertura para a manifestação do que se mostra ao seu olhar. Na relação com o mundo, o Dasein, o nunca, o apreende na sua totalidade, razão pela qual não institui verdades absolutas.

Uma vez lançado no mundo, o homem necessita cuidar do seu próprio existir, fazer, por assim dizer, a si mesmo nas suas muitas ou escassas relações que estabelecem consigo, com o outro e com o mundo. A noção de "cuidado", tematizada por Heidegger ao longo de toda a obra "Ser e tempo", em particular, na segunda parte, representa o fato de que, estando no mundo enquanto ser de angústia, o homem, no incessante movimento de busca de sentido de ser, procura, inexoravelmente, temporalizar o seu existir. Inspirados em Heidegger (1996), o temporalizar, tarefa que é dada a cada um indistintamente, significa a possibilidade de constituir-se humano, criando um singular modo de ser e estar no mundo em relação. "A temporalidade temporaliza, e temporaliza nos modos possíveis de si mesma. São esses que possibilitam a pluralidade dos modos de ser do ser-aí, sobretudo, a possibilidade fundamental da existência própria e imprópria" (Heidegger, 1996, p. 123). Cuidando do existir, o homem comumente imerso na impessoalidade visa articular a si mesmo em um modo de "poder-sermais-próprio", procurando atender, assim, ao clamor da consciência que tende a projetá-lo em diferentes possibilidades de ser.

Entende-se que esse modo de pensar traduz a ideia das muitas possibilidades de o homem aproximar-se mais propriamente, no sentido heideggeriano de estar afinado ("tonalidade afetiva") com o que está ao seu alcance, inserindo em seu projeto existencial o que se the apresenta enquanto algo que para ele faz sentido. Nesse aspecto, cabe destacar que esse olhar que acolhe enquanto presença surge não mais como aquilo que se contrapõe ao sujeito pensante sendo por ele "ob-jezado". Nesse estado de abertura, disposição afetiva para acolher o que se mostra enquanto fenômeno, o homem inicia um modo de pensar, de cunho fenomenológico, que "não é um calcular, mas sim um agradecer [danken], visto que o pensar é devedor [verdankt] a isso" (Heidegger, 1996, p. 102). Assim, não mais regido por um modo de pensar mecanicista, calculador e presunçoso, a daseinsanalyse, inspirada no pensar heideggeriano, mantém-se vinculada à dimensão ôntica do homem, sinalizando que a missão do terapeuta enquanto alguém que se dispõe a estar afetivamente aberto ao fenômeno consiste em facilitar a abertura de seus clientes para si mesmos, para aquilo que, formando a sua essência, obstaculiza atualmente o seu existir.

Sapienza (2007) assevera que, na função de terapeutas, o fenômeno que temos diante de nós é a existência de outro que necessita ser cuidado no sentido de estarmos familiarmente implicados com o seu singular modo de ser e estar no mundo no contato com pessoas, coisas, fatos, e consigo mesmo, o que, no seu 
entender, significa lidar com os muitos significados que envolvem aquele existir, com tudo aquilo que acarreta esperança e sofrimento.

Heidegger (2001a), ao propor algumas reflexões acerca da técnica moderna, aponta que estamos inteiramente "cegos" para a essência da técnica entendida como techné. Aponta que, à medida que pretendemos dominar o mundo e, naturalmente, a nós mesmos através da técnica enquanto meros instrumentos que visam alcançar determinados fins absolutos, em sua pretensiosa, permanente e inabalável verdade, mais distantes e equivocados, encontraremo-nos face ao seu caráter mais próprio. Afirma que a excessiva necessidade de dominação da técnica torna-se tanto mais urgente quanto mais a técnica ameaça fugir do nosso controle.

No contexto da daseinsanalyse, a psicoterapia envolta no sentido grego de techné exige do terapeuta uma mudança de atitude que se caracterize pelo desprendimento de verdades a priori, pela abstenção de um modo de agir presunçoso que pretenda conduzir o paciente a perseguir um projeto que lhe é próprio. "Se a própria psicoterapia for dominada pela técnica, pelo controle, pela montagem e pelo poder, somente se mostrará com clareza o dirigir e simultaneamente o estar atrelado, o não se pertencer, mas o ser conduzido" (Cytrynowicz, 1997, p. 69).

Cytrynowicz (1997) aponta que o falar, na terapia, envolto na intimidade das palavras, não está consolidado em um dizer rigoroso, certeiro no sentido de uma apreensão absoluta do dito, mas no genuíno ouvir o sentido para o qual ele se dirige. Nesse aspecto, o predomínio da fala instituída evidente no discurso daquele que solicita ajuda psicoterapêutica, introjetada no modo da impessoalidade geradora de intensa angústia, clama o profissional a partir do próprio existir humano, em um modo compartilhado de "ser-com", a apreender o seu horizonte de sentido. Portanto, falamos de uma clínica baseada na concepção heideggeriana de cura, como apresentada em Ser e Tempo (1999) e já pontuada. Cura, que pode ser traduzida também por cuidado, é vista como ontológica-existencial; como um preceder-se a si mesma da presença (ser-aí) e abertura de possibilidades no ser-com. Heidegger diferencia esta cura em ocupação e preocupação. A ocupação poderia ser relacionada à técnica criticada pelo autor, uma vez que fala dos cuidados básicos, do encontro repetitivo com o outro, do essencialmente necessário, que fica limitado ao ente. Não há abertura de possibilidades. Já a preocupação poderia ser aproximada da techné, que permite um encontro cuidadoso que se abre para as possibilidades, no qual há envolvimento e interesse pelo outro. Dessa forma, se falamos de uma clínica do cuidado, falamos desta cura preocupada, vinculada ao outro, às suas demandas e necessidades. Um cuidado que não desvincula um do outro: se cuido de mim, necessariamente, estou cuidando do outro. 


\section{A clínica winnicottiana}

Donald Woods Winnicott $(1975,1999 a)$ foi pediatra e, a partir de sua prática com bebês e suas mães e familiares, se tornou psiquiatra e psicanalista. A partir da observação de um número bastante grande de bebês, Winnicott construiu uma teoria psicanalítica sobre sua concepção de pessoa e de amadurecimento humano, e, concomitantemente, de trabalho clínico fundamentado em alguns conceitos básicos, como: "relação mãe-bebê", "criatividade", "confiabilidade", "transicionalidade", "concernimento", entre outros. Ou seja, Winnicott traça uma base importante de relação mãe-bebê para que o bebê possa ser, com toda potencialidade de existir para si e no mundo, e a partir daí, criará um paralelo sobre a atuação do psicanalista ou psicoterapeuta.

Aponta o teórico (1975) que a saúde do indivíduo está inevitavelmente condicionada à qualidade do vínculo estabelecido, em tenra idade, entre o bebê e seu cuidador, mais precisamente no modo como este o segura, o manipula e apresenta o objeto para ele. Privilegiando os primeiros momentos de vida do bebê, destaca que a criatividade, elemento crucial no processo de constituição de si mesmo, representa a capacidade que o sujeito tem de criar o mundo e a si mesmo ao longo do seu desenvolvimento. Esse processo consiste no modo como a mãe exerce as diferentes funções na relação afetiva com ele. A transicionalidade, nesse sentido, efetiva-se à medida que essa mãe, enquanto provedora das reais necessidades desse bebê, dispõe-se efetivamente a articular-se com ele objetiva e subjetivamente na trama de objetos que compõem o seu mundo.

Um ambiente que favorece um "segurar" satisfatório incita o bebê a caminhar em seu amadurecimento pessoal em conformidade com sua tendência à integração - para Winnicott, a primeira experiência é a solidão essencial, marcada pela sensação de não integração, que seria elemento da condição humana; à qual se soma uma inata tendência à integração, ao movimento em busca de existir, que precisa encontrar amparo, neste ambiente facilitador. A consequência desse recurso promove nele um senso de existir fundado em uma experiência de autonomia do seu próprio self (Winnicott, 1999a). Afirma o autor (1999b): "Os cuidados com as crianças giram em torno do termo "segurar", principalmente se permitirmos que seu significado se amplie à medida que o bebê cresce e que seu mundo vai se tornando mais complexo" (p. 53). 0 "segurar", entendido como um ato sensorial não aprendido pela mãe no trato com o bebê, representa, portanto, uma das funções ambientais mais elementares no seu desenvolvimento, considerando ser este o suprimento afetivo básico que viabilizará ou não a criatividade dele nas suas muitas relações com o mundo.

Há necessidade de ressaltar a compreensão da obra de Winnicott em relação a crianças e pacientes que trazem questões mais sérias, com problemas maiores neste processo de amadurecimento. Um ambiente suficientemente bom, 
facilitador do amadurecimento, terá condições de identificar as necessidades do bebê a cada momento e equilibrar gradativamente, de acordo com as capacidades deste, a resposta à demanda. Isso porque a mãe não pode, nem deve estar para sempre ao dispor do seu bebê. Ela precisa ajudá-lo a criar sua capacidade de buscar o que precisa. Nesse trabalho com pacientes mais comprometidos em seu processo de amadurecimento, de integração, Winnicott percebe a importância de acompanhá-los a experiências que permitem a reelaboração de necessidades que não puderam ser atendidas - ao que chamou de regressão. Isso é, o psicanalista entende poder fazer no setting o papel de ambiente facilitador, como na relação mãe-bebê. $O$ paciente reedita suas necessidades que, ao não serem atendidas, reconhecidas, bloquearam 0 desenrolar de seu amadurecimento. E o analista tem possibilidade de reconhecer e acolher esta necessidade, permitindo o prosseguimento do processo de integração.

Em duas palestras proferidas para médicos entre 1960 e 1970, Winnicott fala sobre a implicação do profissional no trabalho clínico e os diferentes matizes que ela adquire de acordo com a necessidade do paciente. Ele deixa bastante claro que não há clínica sem envolvimento, sem preocupação e cuidado com o paciente. Discute, inclusive, que a cura deve estar direcionada a esse cuidado, uma vez que os quadros de doença geram dependência. Uma postura apenas técnica, que aplica tratamento desvinculado de uma atenção maior à pessoa que fala, ao gesto de acolhimento e sustentação, por vezes até corporal, não atenderá às necessidades do paciente: "A psicanálise não se resume a interpretar o inconsciente reprimido; é, antes, o fornecimento de um contexto profissional para a confiança, no qual este trabalho pode ocorrer" (Winnicott, 2005, p. 108).

Esse cuidado implicado, inclinado ao outro, associado ao cuidar preocupado e dedicado da mãe, só é possível a partir do que Winnicott (2005) chama de "a primeira experiência é a": a capacidade de "para penetrar, através da imaginação, e ainda assim de modo preciso, nos pensamentos, nos sentimentos e nas esperanças de outra pessoa, e também de permitir que outra pessoa faça o mesmo com ele" (p. 110). O autor enfatiza essa capacidade como importante para uma relação humana, de contato com o outro e suas reais necessidades e "alcançar efeitos mais profundos". Para tanto, o processo de amadurecimento precisa ter avançado, no sentido de diferenciação eu e não-eu, de noção do outro como fora de seu controle onipotente, da capacidade de estar só na presença do outro, na confiança em si e no mundo de sobrevivência, de preocupação com o outro e cuidado consigo e com este, por perceber que ambos precisam um do outro.

Observa-se que Winnicott percebe a clínica como um cuidado com os pontos bloqueados no processo de amadurecimento, levando a pessoa a confiar no ambiente e poder criar. A criatividade é fundamental para a relação consigo 
mesmo e com o outro. E esse pediatra, psicanalista e pensador (como ele mesmo se denomina) compreende que essa sustentação é fundamental para uma inserção responsável na sociedade: "Em termos da doença social, o "cuidarcurar" pode ser mais importante para o mundo do que a "cura-tratamento" e do que todo diagnóstico e prevenção que acompanham aquilo que geralmente se denomina abordagem científica" (Winnicott, 2005, p. 112). Sendo cuidada a primeira experiência é a essa pessoa pode interagir com o mundo criativamente, construindo relações baseadas no sentimento de que a vida vale a pena ser vivida.

Portanto, a clínica winnicottiana se baseia nessa noção de holding, que permite confiança para elaborar experiência de ser e continuar sendo e assim avançar no processo de amadurecimento. Isto quer dizer que o processo analítico busca a capacidade de brincar, para que a transicionalidade entre o interno e externo seja possível e assim se estabeleça a relação com o mundo. Ou seja, o brincar se estabelece neste espaço transicional, que só é possível com um ambiente de confiabilidade e fidedignidade, quando há confiança de poder criar. O brincar é, em alguns momentos, uma possibilidade lúdica de lidar com a frustração de não ter o controle do mundo, de separar gradativamente o objeto subjetivo, criado pelo bebê, com suas expectativas, do objeto objetivamente percebido, apresentado pela mãe, com suas características. De enfrentar e elaborar as diferentes experiências através da fantasia - destruir sem precisar efetivamente quebrar ou bater, por exemplo. Winnicott coloca duas capacidades como importantes para dar este passo de se relacionar com o mundo de forma integrada e amadurecida: a de estar só e de uso dos objetos.

A primeira tem a ver com a possibilidade de internalizar o holding, não necessitando mais a presença externa do outro, mas podendo confiar neste ambiente que o acompanha. A segunda capacidade diz de esse poder entrar em contato com objetos externos, sem exigir controle total sobre ele, mas podendo fazer uso destes a partir do que há de importante para si. O uso dos objetos se dá a partir da destruição dos objetos subjetivos, criados pela ilusão de onipotência do sujeito em constituição. Ao poder destruí-los, abre-se a possibilidade de contato com o objeto objetivamente percebido (externo), criativamente se relacionando com o que se apresenta e podendo sempre amadurecer a partir dessa relação, que permanentemente contribui para a integração e cuidado consigo. Pelo prazer de criar sua forma de existir em meio às demandas da vida, Winnicott (1975) diz: "Após ser - fazer e deixar-se fazer. Mas ser, antes de tudo" (p. 120).

Algumas articulações entre o "cuidar" e o "segurar" a caminho de um modo de ser psicoterapeuta

Iniciamos essa segunda parte a primeira experiência é a, tanto Heidegger quanto Winnicott, apesar de serem pensadores que formularam solitariamente os 
seus conceitos, não tendo recorrido um ao outro em suas formulações teóricas, o sentido por eles atribuído ao existir humano difere substancialmente da ideia de homem pensado cartesianamente. Ambos formularam questões concernentes ao existir humano nos horizontes ôntico e ontológico (Santos, 2007). Comenta Santos (2007) que Heidegger, após a publicação de "Ser e tempo" (1927), pontuou a necessidade de se pensar o ser-aí nos períodos iniciais do seu desenvolvimento, de modo a elucidarmos ainda mais uma compreensão da nossa condição existencial. No seu entender, à medida que a referida obra destaca que, ao existir humano, é fundamentalmente um acontecer temporal e finito, é possível recorremos à psicanálise proposta por Winnicott. Nesse sentido, destaca o autor que a fenomenologia existencial pode favorecer alguma compreensão dos componentes ontológicos dessa psicanálise, ao tempo em que esta pode também suscitar reflexões ainda pendentes no pensamento heideggeriano. Afirma Loparic (2007):

É difícil não reconhecer que as análises de Heidegger ficaram basicamente incompletas. Em particular, ele não diz nada sobre o problema onto-ontológico do nascimento e nem trabalha a experiência do nascimento propriamente dita. [...] Creio, contudo, que é possível dizer que, a sua perspectiva sobre a vida humana imediatamente pós-natal se coaduna, no essencial, embora não nos detalhes, com a abordagem psicanalítica da vida dos bebês desenvolvida por Winnicott [...] (p. 255)

Destaca Loparic (2007) que, diferentemente da perspectiva heideggeriana, para quem o ser humano já constituiu a externalidade, a visão winnicottiana afirma que a realidade externa é construída gradativamente pelo bebê no início da vida. Quando alguma situação específica lhe provoca tamanho impacto afetivo, invadindo-o, o bebê perde o sentido do real, as suas relações objetais iniciais, acarretando comprometimento na sua identidade primária, e em casos extremos, encerrado em si mesmo, fecha-se no seu mundo subjetivo, passando, assim, a experienciar as angústias impensáveis, que se referem à condição humana de solidão essencial (fruto da situação do nascimento).

[...] o homem só pode tornar-se um existente, alguém que se sente real e que é capaz de estar no mundo e de se relacionar com os outros seres humanos e com as coisas (as primeiras delas sendo os brinquedos) de modo criativo, depois de ter sido acolhido por um colo materno, do qual dependeu totalmente e que foi o seu primeiro lugar para ser (p. 266).

$\mathrm{Na}$ tentativa de fazermos possíveis articulações entre as clínicas daseinsanalítica e winnicottiana, remetendo-nos inicialmente ao que Winnicott (1975) pontua como sendo um dos complicadores no processo de desenvolvimento do bebê, em especial no tocante à formação do seu self, a ausência de a primeira experiência é a, ao olhar para o rosto da mãe, percebe a si mesmo, o que nem sempre para ele representa uma experiência satisfatória. 
Inspirados na noção holding the baby, entendemos que talvez seja essa a função do psicoterapeuta: "segurar", "sustentar" afetivamente um diálogo que, traduzindo patologizantes modos de ser no mundo, encaminha outras formas de existir criativamente, ou seja, em acordo com o self verdadeiro daquela pessoa. Entendemos por "patologizantes modos de ser no mundo", o sofrimento vivido por aqueles que, impactados com a expressiva ausência de sentido face às escolhas feitas, não conseguem dar continuidade à sua existência ou demonstram imensa dificuldade de elaborá-la, razão pela qual buscam ajuda profissional de um psicoterapeuta ou profissionais outros de áreas afins.

Acredita-se que talvez possamos afirmar que o experienciar de uma avassaladora ausência de sentido por parte de clientes que solicitam ajuda psicoterapêutica expresse, grosso modo, a impossibilidade que tais sujeitos têm de "brincar" com o seu existir, no sentido de criar a si mesmo. Portanto, entende-se que é o "segurar", "sustentar" que permite o desenvolvimento da capacidade de brincar, a partir da liberdade conquistada na segurança do ambiente. Assim, aproximando-nos de uma linguagem winnicottiana, destacamos que:

A psicoterapia se efetua na sobreposição de duas áreas do brincar, a do paciente e a do terapeuta. A psicoterapia trata de duas pessoas que brincam juntas. Em consequência, onde o brincar não é possível, o trabalho efetuado pelo terapeuta é dirigido então no sentido de trazer o paciente de um estado em que não é capaz de brincar para um estado em que o é (Winnicott, 1975, p. 59).

Consolidados em Ximenes (2005), que revelam em seus achados, sintomáticos modos de ser psicoterapeuta quando este profissional não se coloca efetivamente a serviço do clinicar, no sentido atribuído por Figueiredo, e nas noções de cuidado proposto por Heidegger e Winnicott, depreendemos que esse profissional, estritamente fincado em olhares teorizantes e consolidado na técnica como mero instrumento de manipulação e controle da subjetividade, tende, assim, a expressar dificuldade de dispor-se a escutar o sofrimento humano na clínica psicológica. Escutar o outro nesse contexto implica em estar disposto a ser tocado pela fragilidade dele em seu atual modo de estar na relação com o mundo. A indisponibilidade afetiva do psicoterapeuta em efetivar a escuta clínica parece, portanto, acarretar fortes prejuízos àquele que necessita ampliar o seu horizonte de sentido. Nesse horizonte de inteligibilidade, acreditamos que o cliente necessita, por assim dizer, de outro que favoreça o transitar em um espaço intersubjetivo, a que Winnicott denomina de espaço transicional. O brincar proposto no vínculo terapêutico enquanto atitude reveladora da criatividade traduziria a possibilidade de tematizar a angustiante condição humana no permanente movimento de busca de sentido, de criação. Estaria, assim, condicionada fundamentalmente, à atitude do psicoterapeuta que se assume enquanto ser no mundo. Isso é, na capacidade do psicoterapeuta de se ver angustiado e não fugir disso, que ele pode sustentar, segurar, o paciente 
em sua angústia, em sua necessidade não atendida, em sua desintegração, e permitir que o espaço transicional se estabeleça.

No caso específico daquele que procura atendimento psicoterapêutico, na condição de "ser-com", entendida por Heidegger (1997) como componente da estrutura do Dasein, solicita do psicoterapeuta a disponibilidade de "[...] ser-amãe apenas a fim de poder ser e, paradoxalmente, de poder ser si mesmo" (Loparic, 2007, p. 269). Depreendemos, com isso, que o atributo de "ser-a-mãe" no universo da clínica psicológica, metaforicamente falando, representaria, assim, a disposição afetiva do psicoterapeuta para "sustentar" ou "segurar", no sentido winnicottiano, o que necessita ser tematizado no diálogo com aquele que busca atribuir sentidos e significados outros ao seu precário modo de existir.

Essa interlocução entre os autores nos parece possível, mesmo que Winnicott (2000) parta de formação pessoal cartesiana e desenvolva certa técnica de atuação. Entendemos que para ambos não há um manual a ser seguido, mas sim uma implicação com o outro, um movimento de identificação com as necessidades daquele que precisa de cuidados para oferecer o ambiente necessário e facilitador do amadurecimento, da elaboração das experiências em direção à liberdade de novas possibilidades.

Se, para o referido autor, a saúde está relacionada à possibilidade de ser espontâneo e verdadeiro, de brincar, é este o grande objetivo da análise facilitar a expressão verdadeira do self; na vertente daseinsanalítica, a meta da psicoterapia consiste na capacidade que o homem tem de criar a si mesmo a partir da angustiante condição de ser lançado no mundo. Compreendemos que a saúde e o existir autêntico são possíveis, então, apenas no enfrentamento do paradoxo do existir. Somente quando é possível ser e não ser, encontrar-se e desencontrar-se consigo mesmo e com o mundo é que falamos em criatividade, em saúde, em existir autêntico.

Em ambas as vertentes psicoterapêuticas, acima expostas, pensamos o trabalho clínico a partir deste acolhimento, desta sustentação, que uma poesia pode facilitar, por exemplo. Ter alguém que acompanhe, que acolha o ser humano em sua expressão integral daquele momento que vive, naquele encontro, e que ajuda a construir diferentes formas de se apropriar de si e do mundo, inclusive através de produções culturais e artísticas. Quer dizer, há um segurar necessário para que a pessoa se aproprie de si, sinta-se capaz de andar sozinha e tenha interesse em fazê-lo. Por isso, ele vem ao lado da apresentação de objetos. E assim, o brincar e a experiência cultural são possíveis e o estarcom e a apropriação do mundo se tornam experiências verdadeiras, autênticas.

\section{CONSIDERAÇÕES FINAIS}

Alguns estudiosos, a exemplo de Loparic e Santos, apontam que Winnicott é o psicanalista mais fenomenólogo que já existiu. Parece-nos que essa 
observação tem pertinência, visto a concepção de que o ser humano sempre está em constituição, sempre necessita de cuidados, de relações com os outros, precisando da capacidade de brincar para que este exercício possa ser criativo e suporte os paradoxos inerentes à condição humana.

Procurando pensar a clínica psicológica para além da técnica moderna, nos remetemos a autores como Safra e Kupermann que vêm desenvolvendo trabalhos sobre a postura clínica, a partir de sua implicação ética e humana. Ambos falam de Winnicott em suas reflexões e da importância do "segurar": "Partindo da solidão essencial, o ser humano entra no mundo na condição de exilado surpreendido, acolhido no abraço e no olhar de alguém para que um lugar se estabeleça e um iniciar-se possa acontecer" (Safra, 2004, p. 24). "O 'manejo' winnicottiano [...] refere-se, ao contrário, à possibilidade de o analista adaptar-se suficientemente bem aos modos de subjetivação do analisando, criando um 'contexto analítico' adequado (Kupermann, 2008, p. 97).

Duas referências que também apontam uma preocupação com a liberdade de escuta e manejo e com a necessidade de sustentar o outro para que ele se constitua um eu que pode existir e buscar cotidianamente sua existência. Figueiredo (1994), ao trazer contribuições da teoria heideggeriana para a clínica psicanalítica, aponta a complexidade de atuação de um terapeuta que se "protege" na teorização. Isso é, se o peso da teoria se torna muito grande, pode amarrar a escuta e o encontro com o paciente. Entendemos aqui a teoria como um brincar.

O analista precisa brincar com o que Ihe suscita o encontro com aquele paciente, para compreender quais elementos são seus, quais são trazidos pelo paciente, o que o paciente necessita e o que o analista quer e pode oferecer. Portanto, é no contato imediato com a condição humana que este percurso lúdico pode acontecer e permitir uma construção de qual norte guiará o encontro com aquele paciente. Lúdico porque deve estar conectado também com o espaço potencial que permite o encontro clínico.

O encontro com a teoria também convoca identificações e conexões que nem sempre podem ser completamente racionalizadas, mas permitem ao paciente lançar-se ao encontro clínico também. Assim, as aproximações entre as clínicas winnicottiana e daseinsanalítica chamam a atenção para esse estofo teórico como uma possibilidade de um brincar que envolva um ir e vir do analista ou psicoterapeuta entre seu angustiante mergulho no encontro clínico e reflexões teóricas que inexoravelmente devem permitir que paradoxos sejam sustentados visando, desse modo, ao movimento de busca de sentido daquele que demanda cuidado.

Marlene Rosemberg, em trabalho apresentado na SBPSP, em 2012, coloca:

A vivência paradoxal é a que inclui abertura, é viver na negatividade, é aceitar que as coisas não são como supúnhamos, a presença do 
outro muda nosso saber, a nossa tradição, e nos abre para uma possível liberdade para criar e recriar o sentido das experiências vividas. O sentido da vida é criado (ou não) continuamente. Portanto o que chamamos de objeto subjetivo é (ou não) continuamente destruído. [...] Como dizia Winnicott, a afirmação mais perigosa de se fazer é EU SOU. E o que inclui o não-eu demanda criação, destruição e recriação contínuas.

Assim, ao lado de textos teóricos de autores preocupados com o sofrimento humano, entendemos que as produções culturais, como poesia, literatura, filosofia, pinturas, fotografia, música, etc., se incluem neste material, lúdico, que sustenta a reflexão clínica. Pois falamos de poder encontrar um holding no ambiente, de internalizar um ambiente facilitador e assim sustentar o paradoxo nesta possibilidade de liberdade de relação, de criação, de uso do que se apresenta para existir de forma verdadeira, em contato com seu entorno de forma prazerosa: na sensação de poder ser, mais do que poder explicar o ser, o existir.

\section{REFERÊNCIAS}

Calazans, R. (2008). Psicanálise: clínica da escuta, clínica do sujeito pulsional. Revista de Psicanálise, 21(1), 18-25.

Cytrynowicz, M. B. (1997). Psicoterapia: uma aproximação daseinsanalítica. Revista da Associação Brasileira de Daseinsanalyse, 4, 63-70.

Doron, R. \& Parot, F. (Eds.) (1998). Dicionário de Psicologia. São Paulo: Ática.

Dutra, E. (2004). Considerações sobre as significações da psicologia clínica na contemporaneidade. Estudos de Psicologia, 9(2), 381-387. doi: 10.1590/S1413-294X2004000200021

Figueiredo, L.C.M. (1994). Escutar, recordar, dizer. Encontros heideggerianos com a clínica psicanalítica. São Paulo, SP: Educ/Escuta.

Figueiredo, L.C.M. (2004). Revisitando as Psicologias: Da Epistemologia à Ética das Práticas e Discursos Psicológicos. Petrópolis, RJ: Vozes.

Guerra, A. M. C. (2002). O Social na Clínica e a Clínica do Social: Sutilezas de uma Prática. In B. D. Gonçalves; A.M.C. Guerra, \& J. O. Moreira (Eds.), Clínica e Inclusão Social: Novos Arranjos Subjetivos e Novas Formas de Intervenção (pp. 29-48). Belo Horizonte, MG: Edições do Campo Social.

Heidegger, M. (2001a). Ensaios e conferências. (E. C. Leão, G. Fogel, \& M. S. C. Schuback, Trans.). Petrópolis, RJ: Vozes.

Heidegger, M. (2001b). Seminários de Zollikon (G. Arnhold \& M. F. A. Prado, Trans.). Petrópolis, RJ: Vozes.

Heidegger, M. (1997). Ser e tempo - Parte I. Petrópolis, RJ: Vozes.

Heidegger, M. (1996). Ser e tempo - Parte II. Petrópolis, RJ: Vozes.

Kupermann, D. (2008). Presença sensível: Cuidado e criação na clínica psicanalítica. Rio de Janeiro, RJ: Civilização Brasileira. 
Levy, P. (2001). A Conexão Planetária: O Mercado, O Ciberespaço, A Consciência. São Paulo: Editora 34.

Loparic, Z. (2007). Origem em Heidegger e Winnicott. Natureza Humana, 9(2), 243-273.

Safra, G. (2004). A pó-ética na clínica contemporânea. Aparecida, SP: Ideias e Letras.

Romagnolli, R.C. (2006). Algumas reflexões acerca da clínica social. Revista do Departamento de Psicologia - UFF, 18(2), 47-56. doi: 10.1590/S010480232006000200004

Rosemberg, M. (2012, outubro). Tradição e paradoxo no viver criativo: criação/destruição/encontro. Apresentação oral no $29^{\circ}$ Congresso da FEPAL Intervenção-Tradição, São Paulo, SP.

Santos, E.S. (2007). Winnicott e Heidegger: Indicações para um estudo sobre a teoria do amadurecimento pessoal e a acontecência humana. Natureza Humana, 9(1), 29-49.

Sapienza, B. T. (2007). Do desabrido à confiança: Daseinsanalyse e terapia. São Paulo, SP: Escuta.

Ximenes, C.M.A. (2005). O sentido de ser sintoma na clínica psicológica. (Dissertação de mestrado não publicada). Universidade Católica de Pernambuco, Recife.

Winnicott, D. (1991). Holding e Interpretação. (S. M. T. M. Barros, Trad.). São Paulo: Martins Fontes. (Obra original publicada 1986).

Winnicott, D. (1975). O brincar e a realidade (J. O. A. Abreu \& V. Nobre, Trads.). Rio de Janeiro, RJ: Imago. (Obra original publicada 1971).

Winnicott, D. (1999a). Os bebês e suas mães. (J. L. Camargo, Trad.). São Paulo, SP: Martins Fontes. (Obra original publicada 1987).

Winnicott, D. (1999b). Tudo começa em casa. (P. Sandler, Trad.). São Paulo, SP: Martins Fontes. (Obra original publicada 1986).

Winnicott, D. (2000). Da pediatria à psicanálise. (J. Russo, Trad.). Rio de Janeiro, RJ: Imago. (Obra original publicada 1958).

Winnicott, D. (2005). A família e o desenvolvimento individual. (M. B. Cipola, Trad.). São Paulo, SP: Martins Fontes. (Obra original publicada 1965). 
Sobre os autores

Celina Maria Aragão Ximenes é pela Universidade Federal de Sergipe (UFS), mestre e doutoranda em Psicologia Clínica pela Universidade Católica de Pernambuco (UNICAP), especialista em psicoterapia fenomenológica existencial pela Pontifícia Universidade Católica de Minas Gerais (PUC-MG). Trabalha na perspectiva fenomenológica existencial de inspiração heideggeriana. E-mail: celximenes@uol.com.br

Mariana Peres Stucchi é psicóloga e mestre pelo Instituto de Psicologia da Universidade de São Paulo (USP), doutoranda em psicologia clínica pela Universidade Católica de Pernambuco (UNICAP). Trabalha na perspectiva da psicanálise. E-mail: maristucchi@yahoo.com.br

Wellington Martins de Lira é psicólogo pela Universidade Federal de Pernambuco (UFPE), mestre e doutorando em psicologia clínica pela Universidade Católica de Pernambuco (UNICAP), especialista em Terapia Familiar pela Universidade Federal de Pernambuco (UFPE), especialista em Saúde Mental Infanto Juvenil pela Escola de Ciências Médicas de Alagoas (UNCISAL). Trabalha nas perspectivas sistêmica, fenomenológica existencial e logoterapia. E-mail: delirawm@bol.com.br

Recebido em: 04/03/2015 Revisado em: 12/05/2015 Aceito em: 07/07/2015 